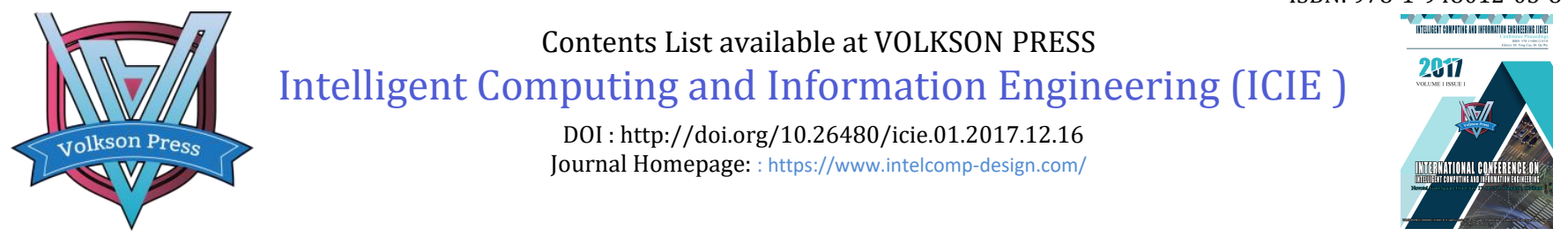

\title{
Design of Interactive Virtual Maintenance Training System for Vehicular Automatic Weapons
}

\author{
WANG Lei ${ }^{*}$, LI Hua ${ }^{2}$, SU Zhong-ting ${ }^{2}$ \\ (Department of Arms Engineering, Academy of Armored Force Engineering, Beijing, China) \\ *email:suzt1984@163.com
}

This is an open access article distributed under the Creative Commons Attribution License, which permits unrestricted use, distribution, and reproduction in any medium, provided the original work is properly cited

\section{ARTICLE DETAILS}

\section{Article History:}

Received 12 May2017

Accepted 12 July 2017

Available online 14 September 2017

\section{Keywords:}

barbette circle; clearance ; ball bearing ; contact.

\section{ABSTRACT}

The vehicular automatic weapons interactive virtual maintenance training system was designed applying 3D Solid Modeling and interactive virtual simulation techniques aiming at the problems of such as low training efficiency and went short of training resource. The virtual maintenance implement process was expatiated, then the dummy scape display module, graphical user interface, consumer operating event driven module and maintenance operation control module were built up, lastly, the movie and interactive training were designed applying $3 \mathrm{ds}$ max and NGRAIN software, the vehicular automatic weapons interactive virtual maintenance training flat roof was established, which could improve on the teaching and training pattern, advance the equipment utilizing rate and training effect, and overcome the shortage in the teaching and training presently.

\section{Introduction}

The vehicular automatic weapons are the compound weapons of armored vehicle which are used for annihilating and pressing the enemy over tank enginery, light armoring target and infantries [1]. The accouter fitting out the automatic weapons were very rifeness and the application was very abroad in modern times, so the teaching and training for the automatic weapons structure and maintain were very important [2].

The automatic weapons have complex structure and nicety assemble relationship though they have smaller size relative to other great arming [3]. So, the problems such as hard sledding, taking time, weak effect of be familiar with structure and process principium contemporary, finite arming using time, arming wasting and hard to clear the inside structure and dynamic process principium [4]. The expansion of arming structure teaching and training is not convenience as a result of the short training resource. So, they cry for a suit of effective vehicular automatic weapons structure and maintain training system [5].

Virtual training is a kind of simulation technic achieved by computer dummy realism technic which can increase the teaching effect availably for arming teaching, breaking down and maintain training [6].

This article designs the interactive movie and interactive training assignment by program exploitation and dummy realism execution taking a kind of automatic gun as research object, opens out the vehicular automatic weapons interactive virtual maintenance training flat roof, affords the novelty and effective technic means for hoisting weapon structure and maintain teaching and training.

\section{THE EXPLOITATION OF VIRTUAL MAINTAIN FLAT ROOF}

\subsection{The process of virtual maintain}

Virtual maintain can be apprehended as the numeric of general maintain which including with virtual tear down, virtual service and virtual assemble [7,8]. But it is not only the numeric of tear down, service and assemble, but also the unification of these three based on the general maintain [9,10]. So essentially, the general maintain is a kind of idiographic physics process, and virtual maintain is a kind of mathematics process based on the logic estimation and correlation operation management. The theory is shown as Figure1.

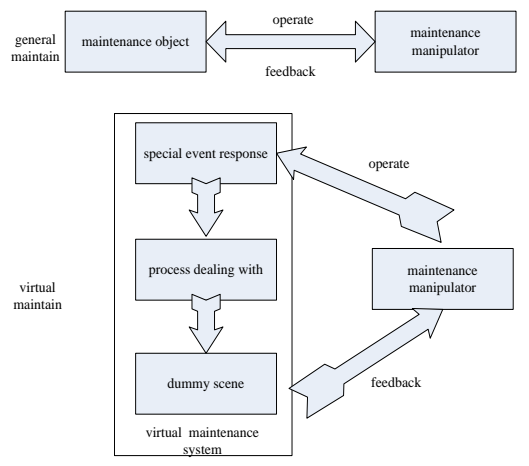


Figure 1: The realization process of general maintain and virtual maintain

\subsection{Interactive virtual training system}

The virtual maintain simulation flat roof is compartmentalized by system function module 3D display module and operate control module to increase the effect of simulation flat roof, and the operate control module includes the structure directory tree, 3D movie and interactive training.

The function structure frame of training system is shown as Figure 2.

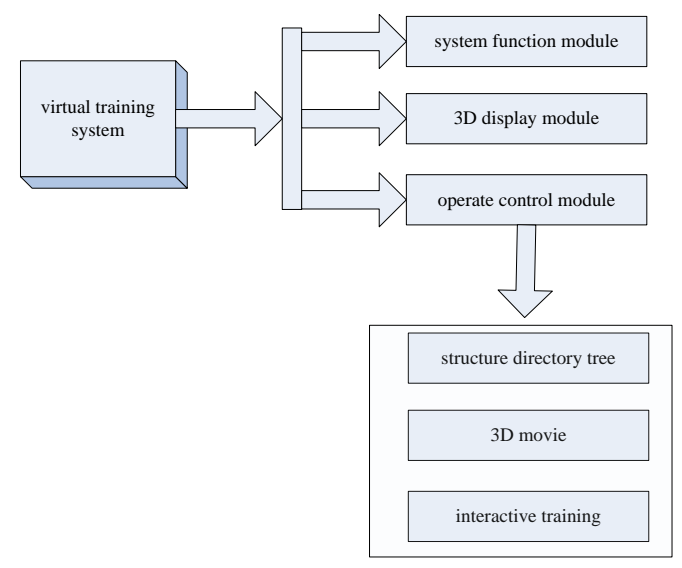

Figure 2: The function frame of vehicular automatic weapons virtual maintenance training system

\section{THE EXPLOITATION OF VIRTUAL MAINTAIN TRAINING MODULE}

The flow of virtual maintain training module includes of 3D model foundation, leading to 3Ds max software, enactment material, leading to NGRAIN software, NGRAIN setting, movie design and interactive training design which is shown as Figure 3.

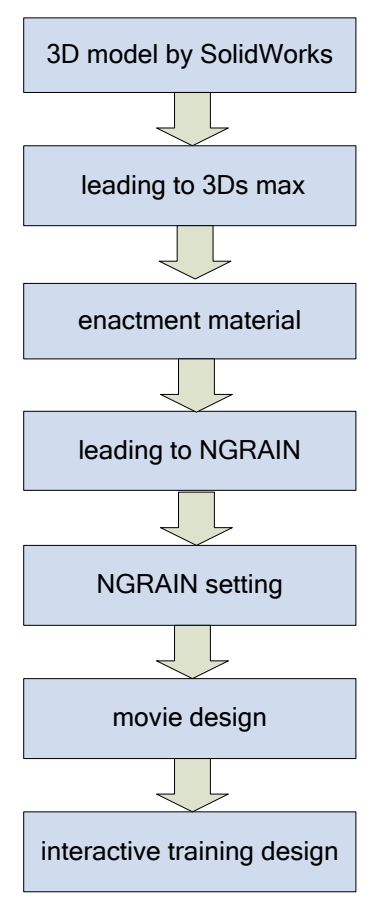

Figure 3: Flow of virtual maintain training module

\subsection{D model by SolidWorks}

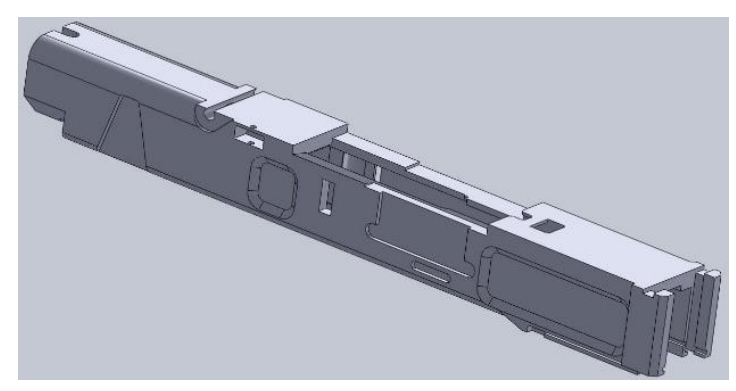

Figure 4: The accessory model 


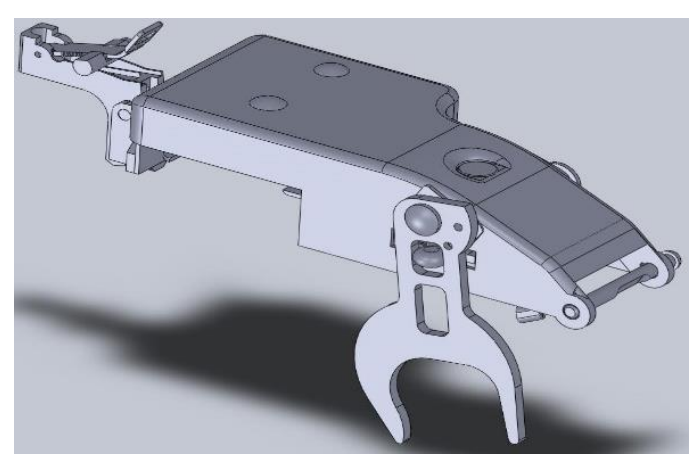

Figure 5: The assemble model

The 3D modeling is the foundation and precondition of the whole virtual maintain training system. The entity model in the vir tual training environment is the important factor of the whole virtual maintain training environment. The accessory model and the assemble model are built up according to the entity arming data and drawing data which are shown as Figure 4 and Figure 5.

\subsection{Movie design}

The 3D modeling built up by SolidWorks software can be leading to the 3Ds max software by a certain type and before the movie design, the visual angle should be adjusted in the working window firstly. The reference axis of the joint is selected by the angle window and the force orientation which is shown as figure 6.

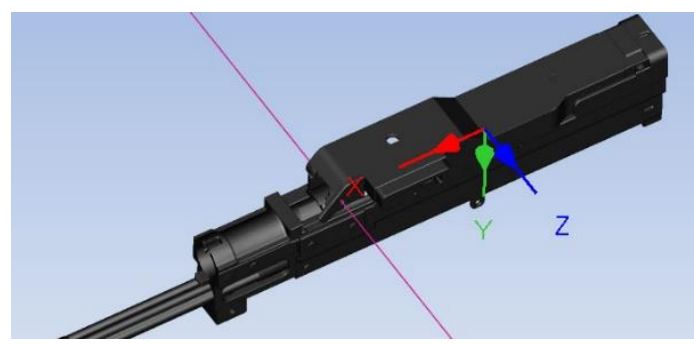

Figure 6: The reference axis of the joint

The minimum and maximum angles of the constrained suffering ball machine casing which can rotate around the hinge are specified which is shown as figure 7.

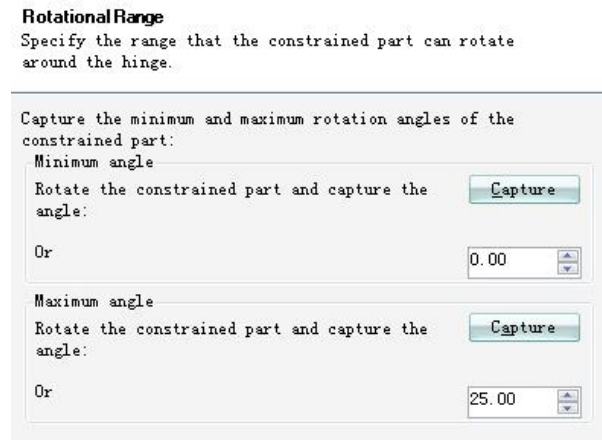

Figure 7: The minimum and maximum angles setup

The location of some assembly is changed, and the timeline location is hit, then the new frame is appended to the timeline.

After the newer frame is captured and the locations of some parts of assembly are changed, the frames are appended in return. The movie design is shown as figure 8.

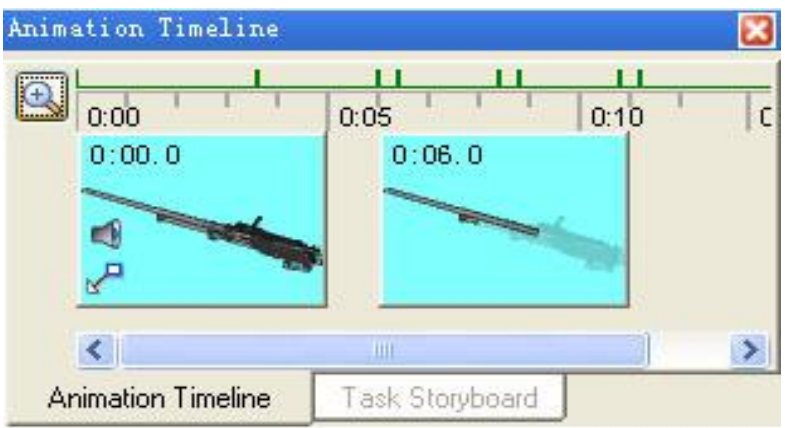

a) animation timeline 1 


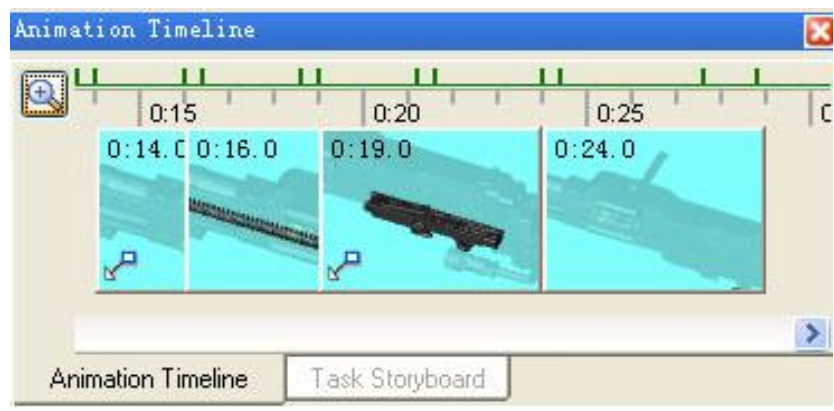

b) animation timeline 2

Figure 8: Animation timeline

\subsection{Interactive training design}

The interactive training system must response the motion of user import. The event driven contains the event reality and event response content. Many event realities can deal with one event response content, but one event reality cannot deal with many event response contents.

Under the tear down mode, the mouse left key can be spot thrash on a certain location to achieve the accessory snatch operation in the virtual scene for the sake of convenience user to select the accessory.

The remark of every step is appended by setting the Properties panel, and the little clew will be shown on the top of every movie, the remarks are shown as figure 9.

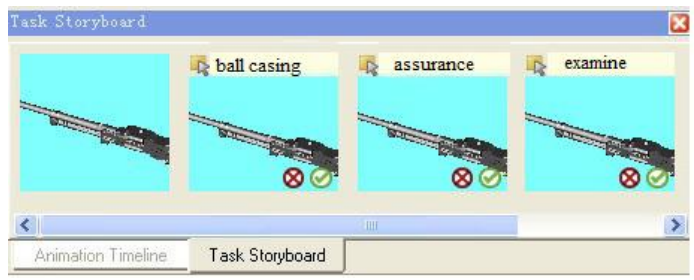

a) the first three remarks

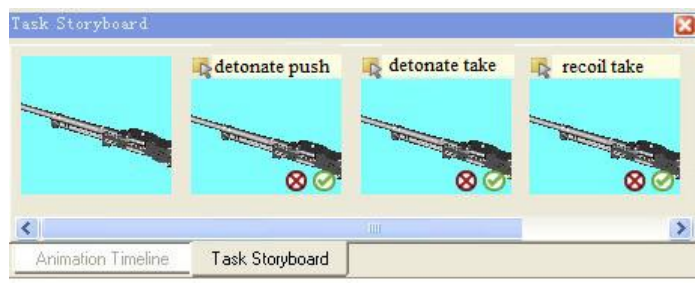

b) the last three remarks

Figure 9: The remarks

\section{CONCLUSION}

The maintain training system adopts the Microsoft Visual Studio 2008 develop environment and NGRAIN PKM virtual module, the computer adopts P4 upwards machine and the software abets WINXP3 and upper operating system.

The keystone of maintain training is manipulation in fact and the difficulty is how to recur the principium by practicality connection. When the students can achieve the basic maintain movement by interactive virtual maintain training system, they will take the reins of correct dismantle sequence and maintain strategy on the real arming flat roof, and they will avoid the dangerous operation because of the manipulation mistake. So, the interactive virtual maintain training system can increase the efficiency of teaching, advance the using rate of maintain equipment, reduce the risk of real training and enhance the security.

\section{REFERENCES}

[1] Burdea, G., Coifet, P. 2004. Virtual real technology. USA: wiley Interscience, 464 p. ISBN: 978-0-471-36089-6.

[2] Xiao-jun, Z., Shao-song, M., Yum-ming, Y. 2006. Research on Maintainability Virtual Verification System of Ship. China Ship Repair, (12), 40-42.

[3] Yi, Z., Jian-zhong, S., Yu-jun, C., Yong-min, Y. 2009. Research on Visibility Evaluation Methods in Maintainability Design. Journal of Engineering Graphics, 30 (1), 71-74.

[4] Yong-feng, D. 2005. Research on Maintainability Virtual Analysis and Verification Methods of Civil Airplane. Nanjing University of Aeronautics and Astronautics the Graduate School College of Civil Aviation, 12.

[5] Kang, J.Y., Min, L.X. 2013. Simulation Method of Equipment's Interactive Virtual Maintenance Process Based on Stateflow/Virtools. Computer Measurement and Control, 21 (10), 2792-2795.

[6] Lu, W. 2009. Research on Virtual Assembly of Ground Based High Mobility Radar Structure. Radar Science and Technology, 7 (2), $158-162$. 
[7] Vujosevic, R., Raskar, R., Yetukuri, N.V., Jothishankar, M.C., Juang, S.H. 1995. Simulation, Animation and Analysis of Design Disassembly for Maintainability Analysis. International Journal of Production Research, 33 (11), 2999-3022.

[8] Di-jiang, C., Hong-qi, Z., Xing-yu, C. 2010. Research on High Efficient Virtual Maintenance Technology of Ground Based Radar Structure. Radar Science and Technology, 18 (6), 576-579.

[9] Bartlomiej, A., Wilhelm, T., Paul, M. 2008. Maintenance of complex machines in electric power systems using Virtual Reality techniques. Conference Record of IEEE International Symposium on Electrical Insulation, 2008 IEEE International Symposium on Electrical Insulation, 483-487.

[10] Barry, R. 2002. Lockheed martin demonstrates virtual maintenance software. Aviation weeks and space technology, 156 (14), $89-92$. 